\title{
61. Expression of a Dystrophin-like Protein on the Surface Membrane of Muscle Cells in mdx Mice
}

\author{
By Hikaru Tanaka, Teruo Shimizu, and Eijiro Ozawa \\ National Institute of Neuroscience, NCNP, Kodaira, Tokyo 187
}

(Communicated by Setsuro Ebashi, м. J. A., Dec. 12, 1989)

Introduction. Duchenne muscular dystrophy (DMD) is a degenerative muscle disease which results from a single gene defect on the $\mathrm{X}$-chromosome. The gene product, dystrophin, is located on the cytoplasmic face of the cell surface membrane in skeletal and cardiac muscles, but is absent in muscle from DMD patients (Sugita et al., 1988; Zubrzycka-Gaarn et al., 1988; Arahata et al., 1988; Watkins et al., 1988; Bonilla et al., 1988; Shimizu et al., 1988; Hagiwara et al., 1989; Hoffman et al., 1988; Tanaka et al., 1989), this is currently believed to be the primary cause of muscle fiber degeneration in DMD.

The $m d x$ mouse is an $\mathrm{X}$-chromosome linked recessive myopathic mutant which is devoid of dystrophin (Hoffman et al., 1987, 1988; Arahata et al., 1988), and it is therefore widely used as an animal model of human DMD. It has a single base substitution within the dystrophin gene exon; this is considered to cause premature termination of the polypeptide chain (Sicinski et al., 1989).

In the present study, we found that an antiserum raised against the Cterminal region of dystrophin reacts with a $400 \mathrm{kDa}$ protein and stains the skeletal muscle surface membrane in $m d x$ mice. We are at present of opinion that an unknown dystrophin-like protein is expressed on the surface membrane of $\operatorname{mdx}$ mice.

Materials and methods. Immunoblot analysis and immunohistochemistry were performed according to the methods previously described (Hagiwara et al., 1989). The samples used were tibialis anterior and cardiac ventricular muscle samples from 10-week old wild type (C57BL/ScSn) and $m d x$ (C57BL/ScSn-mdx) mice. Two different antibodies against dystrophin were used. One was a monoclonal antibody (A1C culture supernatant; Shimizu et al., 1988) raised in mouse against a synthetic polypeptide fragment corresponding to the $\mathrm{N}$-terminal region (residues from 215 to 264) of the amino acid sequence of human dystrophin deduced from cDNA (Koenig et al., 1988). The other was an antiserum (P34a) raised in rabbits against another synthetic polypeptide fragment corresponding to the C-terminal region (residues from 3495 to 3544 ) by the methods previously described (Tanaka et al., 1989). The antiserum P34a used here was a different lot from the P34c used in our previous report (Tanaka et al., 1989), although these antisera were raised against the same antigen peptide.

Results. Immunoblot analyses. A1C stained a band in samples of skeletal and cardiac muscles from wild type mice, whose molecular weight was about $400 \mathrm{kDa}$. This band was absent in the samples of skeletal and cardiac muscles from $m d x$ mice (Fig. 1, lanes 1 and 2 for skeletal muscle).

P34a also stained the $400 \mathrm{kDa}$ band in samples of skeletal and cardiac muscles from wild type mice. In samples from $m d x$ mice the $400 \mathrm{kDa}$ band was clearly stained by P34a (Fig. 1, lanes 3 and 4 for skeletal muscle), although weaker than in muscles from wild type mice. 


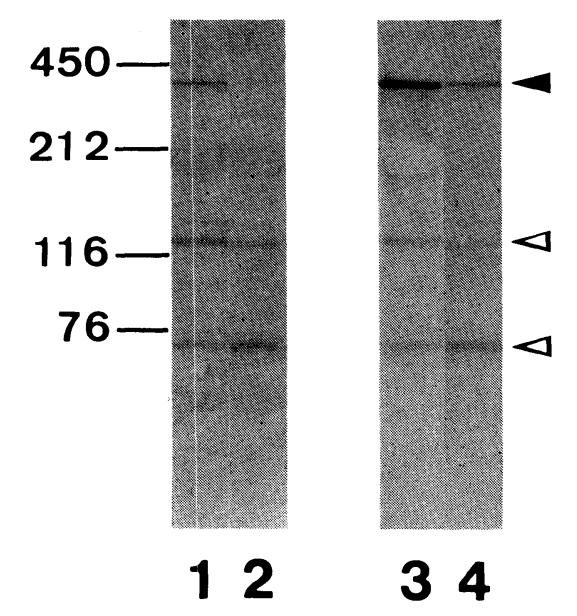

Fig. 1. Immunoblot analysis of wild type and $m d x$ skeletal muscles. Tibialis muscle extracts corresponding to $1 \mathrm{mg}$ of wet tissue from wild type $(1,3)$ and $m d x$ mice $(2,4)$ were electrophoresed, electroblotted to a nitrocellulose sheet and allowed to react with the antidystrophin antibody either $\mathrm{A} 1 \mathrm{C}(1,2)$ or $\mathrm{P} 34 \mathrm{a}(3,4)$. The reaction was visualized with an ABC kit (Vectastain, Vector Laboratories, Inc., Burlingame, California, USA). Molecular weight markers: $450 \mathrm{kDa}$ (Cooper et al., 1981), laminin; 212, myosin heavy chain; 116, beta-galactosidase; 76, transferrin (Pharmacia electrophoresis calibration kit). (4): dystrophin. The two bands commonly stained in all samples $(\triangleleft)$ are artifacts probably due to some avidin binding proteins, because they were observed when the staining was performed without antibodies.

The bands corresponding to molecular weights of about 70 and $120 \mathrm{kDa}$ are artifacts probably due to some avidin binding proteins in the extracts, because they were also observed when the immunostaining was performed only with avidin conjugated catalase and without antibodies (data not shown).

Immunohistochemistry. A1C stained the entire surface membrane in the skeletal and cardiac muscles from wild type mice, but not in muscles from $m d x$ mice (Fig. 2, panels 1 and 2 for skeletal muscle). With P34a, the entire surface membrane was stained in the skeletal and cardiac muscles in wild type mice. In $m d x$ muscles, some fibers were stained with P34a on the surface membrane while others were scarcely stained. In some fibers the immunostaining was discontinuous or partial along the surface membrane. The stained and unstained fibers tended to be present in groups respectively (Fig. 2, panels 3 and 4 for skeletal muscle).

Discussion. The monoclonal antibody $\mathrm{A} 1 \mathrm{C}$ was previously shown to react specifically with dystrophin in human muscle (Shimizu et al., 1988). In the present study, A1C also reacted with a $400 \mathrm{kDa}$ protein in muscles of wild type mice. The molecular weight of human dystrophin deduced from the cDNA sequence is $427 \mathrm{kDa}$ (Hoffman et al., 1987a; Koenig et al., 1988), but is reported to be about $400 \mathrm{kDa}$ in immunoblot analyses (Hoffman et al., 1987b; ZubrzyckaGaarn et al., 1988; Kundson et al., 1988; Hagiwara et al., 1989; Tanaka et al., 1989). The protein was present on the cell surface membrane in muscles from 


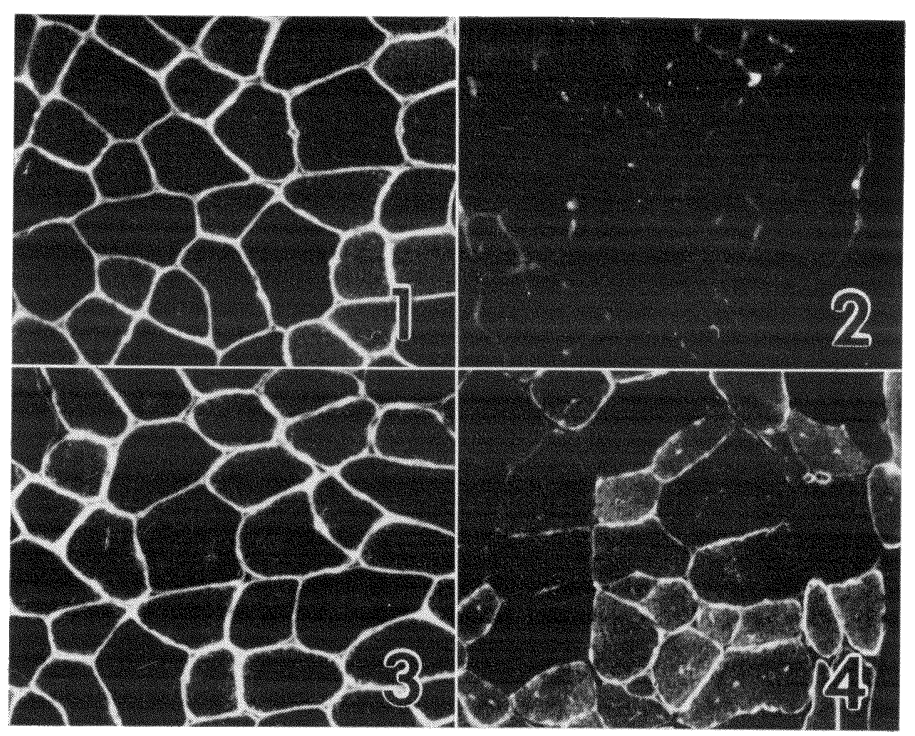

Fig. 2. Frozen sections of tibialis muscle fibers from wild type $(1,3)$ and $m d x$ mice $(2,4)$ stained with A1C $(1,2)$ and P34a $(3,4)$ by the indirect fluorescence method. P34a but not A1C stained the surface membrane in $m d x$ muscle. The faint fluorescence observed in panel 2 was considered to be non-specific because similar results were obtained with preimmune serum. $(\times 800)$

wild type mice, but was absent in $m d x$ muscles. Therefore, A1C specifically reacts with dystrophin in the skeletal and cardiac muscles of mice also.

The antiserum P34a showed similar immunoreactivity to A1C in wild type mice muscles. In $m d x$ muscles, however, P34a reacted with a $400 \mathrm{kDa}$ protein and stained the cell surface membrane. Does this mean that dystrophin is expressed on the surface membrane of $m d x$ muscle? Previous (Hoffman et al., 1987, 1988; Arahata et al., 1988) and our present results with A1C have shown that dystrophin is absent in $m d x$ muscle. Very recently, Sicinski et al. (1989) reported that the $m d x$ mouse has a nonsense mutation within the dystrophin gene exon which results in premature termination of translation at $27 \%$ of the length of the dystrophin polypeptide, and predicted that $m d x$ would synthesize a truncated protein with a molecular weight of $115 \mathrm{kDa}$. This means that the C-terminal region of dystrophin would not be synthesized in $m d x$ mouse muscle. On the other hand, as the amino acid sequence of the antigen polypeptide for P34a was synthesized following the sequence of C-terminal domain located beyond the putative premature termination site, and the same sequence is not found in the truncated dystrophin (Koenig et al., 1988), the antiserum would not recognize the truncated polypeptide. In fact, in immunoblot analysis, the $400 \mathrm{kDa}$ protein was the only protein detected by P34a in $m d x$ muscle (Fig. 1, lane 4). Further, as shown by our present results with $\mathrm{A1C}$ as well as other reports (Hoffman et al., 1987b, 1988a, b; Arahata et al., 1988), the antibodies raised against parts of dystrophin which must be present in the truncated $m d x$ polypeptide, have not yet detected such as protein in $m d x$ muscle. Therefore, the protein detected by P34a in the $m d x$ muscle is neither normal dystrophin nor the truncated $m d x$ dystrophin.

Alternatively, it is highly plausible that an unknown protein with similar 
electrophoretic mobility to dystrophin is expressed on the surface membrane of $m d x$ muscle fibers. Since this protein reacted with P34a whose antigen has the predicted amino acid sequence of the dystrophin C-terminal region, the protein is also expected to have such an amino acid sequence. In this connection, it is interesting that a fragment from the C-terminal region of dystrophin complimentary DNA detects a closely related sequence which identifies a 13-kb transcript in human fetal muscle and maps to chromosome 6 (Love et al., 1989). The deduced polypeptide contains an amino acid sequence which shows $73 \%$ identity with the peptide recognized by $\mathrm{P} 34 \mathrm{a}$; this similarity increases to $83 \%$ if conservative amino acid substitutions are taken into consideration. Although its expression and cellular localization are unknown at present, the gene product is a strong candidate for the dystrophin-like protein observed in the present study.

From these considerations, we are at present of opinion that a $400 \mathrm{kDa}$ protein, similar to but different from dystrophin, is expressed on the surface membrane of skeletal and cardiac muscles in $m d x$ mice.

Acknowledgments. The authors express their thanks to Drs. Tsuneo Ishiguro and Chikahiko Eguchi of Ajinomoto Co. Inc. for providing the synthetic polypeptides, and to Dr. Tetsuya Matsuzaki and Mr. Kenichi Suzuki for providing the experimental animals. This study was partially supported by a Grant (62-1) from the National Center of Neurology and Psychiatry (NCNP) of the Ministry of Health and Welfare, Japan.

Note added in proof. Very recently, Hoffman et al. (Lancet Nov. 18, 1989. pp. 1211-1212) have reported that an antiserum against the C-terminal of dystrophin reacted with a $400 \mathrm{kDa}$ protein in immunoblot analysis of muscles from a patient with total deficiency of dystrophin gene and from $m d x$ mice.

\section{References}

Arahata, K. et al.: Nature, 333, 861-863 (1988).

Bonilla, E. et al.: Cell, 54, 447-452 (1988).

Hagiwara, Y. et al.: Protoplasma, 151, 11-18 (1989).

Hoffman, E. P., Brown, R. H., and Kunkel, L. M.: Cell, 51, 919-928 (1987a).

Hoffman, E. P. et al.: Nature, 330, 754-758 (1987b).

Hoffman, E. P. et al.: New England J. Med., 318, 1363-1368 (1988a).

Hoffman, E. P. et al.: Neuron, 1, 411 (1988b).

Koenig, M., Monaco, A. P., and Kunkel, L. M.: Cell, 53, 219-228 (1988).

Kundson, C. M. et al.: J. Biol. Chem., 263, 8480-8484 (1988).

Love, D. R. et al.: Nature, 339, 55-58 (1989).

Shimizu, T. et al.: Proc. Japan Acad., 64B, 205-208 (1988).

Sicinski, P. et al.: Science, 244, 1578-1580 (1989).

Sugita, H. et al.: Proc. Japan Acad., 64B, 37-39 (1988).

Tanaka, H. et al.: Protoplasma (1989) (in press).

Watkins, S. C. et al.: Nature, 333, 863-866 (1988).

Zubrzycka-Gaarn, E. E. et al.: ibid., 333, 466-469 (1988). 